\title{
Advanced Oropharyngeal Cancer Can Be Easily Missed During Esophagogastroduodenoscopy
}

\author{
Kenta Hamada, Tomofumi Akasaka, Yasushi Yamasaki, Ryu Ishihara \\ Department of Gastrointestinal Oncology, Osaka Medical Center for Cancer and Cardiovascular Diseases, Osaka, Japan
}

Received: $11 / 02 / 2017$

Accepted: 20/02/2017

Published: $27 / 02 / 2017$

\begin{abstract}
How to cite this article: Hamada K, Akasaka T, Yamasaki Y, Ishihara R. Advanced oropharyngeal cancer can be easily missed during esophagogastroduonenoscopy. EJCRIM 2017;4: doi:10.12890/2017_000597.
\end{abstract}

Conflicts of Interests: The Authors declare that there are no competing interests.

This article is licensed under a Commons Attribution Non-Commercial 4.0 License

\section{ABSTRACT}

The case of an elderly man with an advanced oropharyngeal cancer that was missed during esophagogastroduodenoscopy is described. He was referred for endoscopic resection of superficial esophageal squamous cell neoplasms. He died a month after referral due to an advanced oropharyngeal cancer with a metastatic lesion to the brain. Patients with esophageal squamous cell carcinoma are high risk for head and neck cancer. The pharynx is the most common site for cancer in the head and neck region. Consequently, the pharynx should be observed carefully when patients with esophageal squamous cell carcinoma undergo esophagogastroduodenoscopy.

\section{LEARNING POINTS}

- Head and neck cancer develops in approximately $10 \%$ of patients with esophageal squamous cell carcinoma.

- Thepharynxshouldbeobservedcarefullywhenpatientswithesophagealsquamouscellcarcinomaundergoesophagogastroduodenoscopy because the pharynx is the most common site for cancer in the head and neck region.

- Sedation using narcotic drugs can reduce the gag reflex but still allow patients to vocalize and offer adequate conditions for pharyngeal observation during esophagogastroduodenoscopy.

\section{KEYWORDS}

Esophageal squamous cell carcinoma; head and neck cancer; pharyngeal cancer

\section{CASE DESCRIPTION}

Two years prior to his current presentation, a man in his 70s underwent esophagogastroduodenoscopy (EGD) which resulted in the detection of two superficial esophageal squamous cell neoplasms. However, as he declined treatment, follow-up EGDs were performed every 6 months. The lesions gradually spread laterally. He finally requested treatment for the esophageal neoplasms and was referred to hospital for endoscopic resection. An EGD performed 3 weeks after his previous EGD revealed an advanced oropharyngeal cancer in the right glossotonsillar sulcus (Fig. 1, 2). He was referred to an otorhinolaryngologist for further investigation. Computed tomography revealed a metastatic lesion to the brain.

He received palliative care and died a month after referral to hospital. 


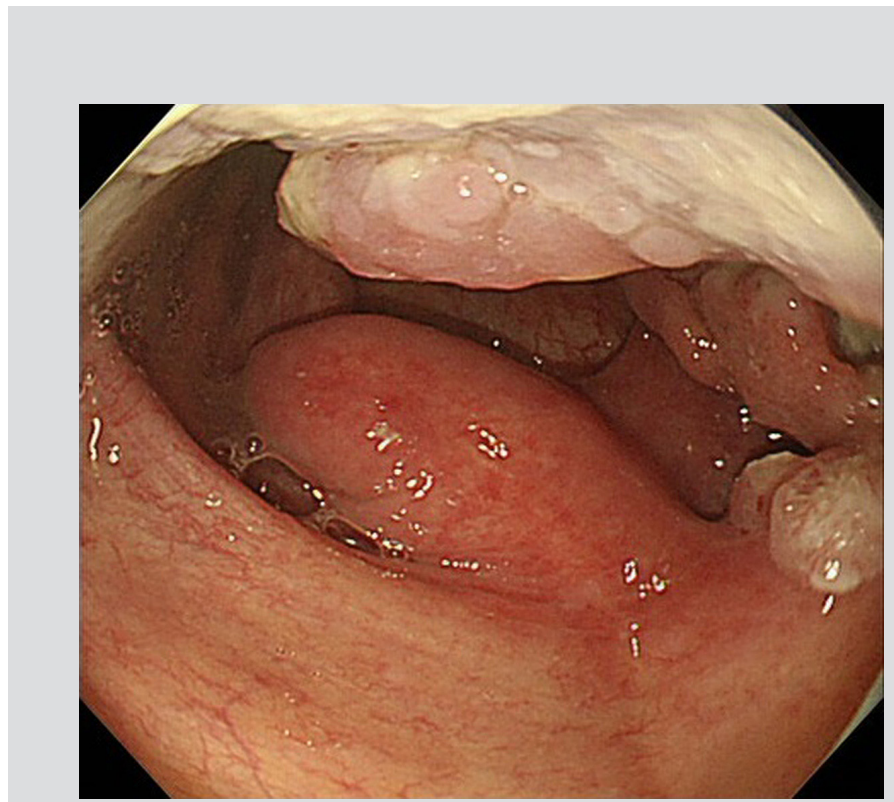

Figure 1. Esophagogastroduodenoscopy performed three weeks after patient's last esophagogastroduodenoscopy showing the normal uvula at the center but irregularity on the right lateral wall of the oropharynx

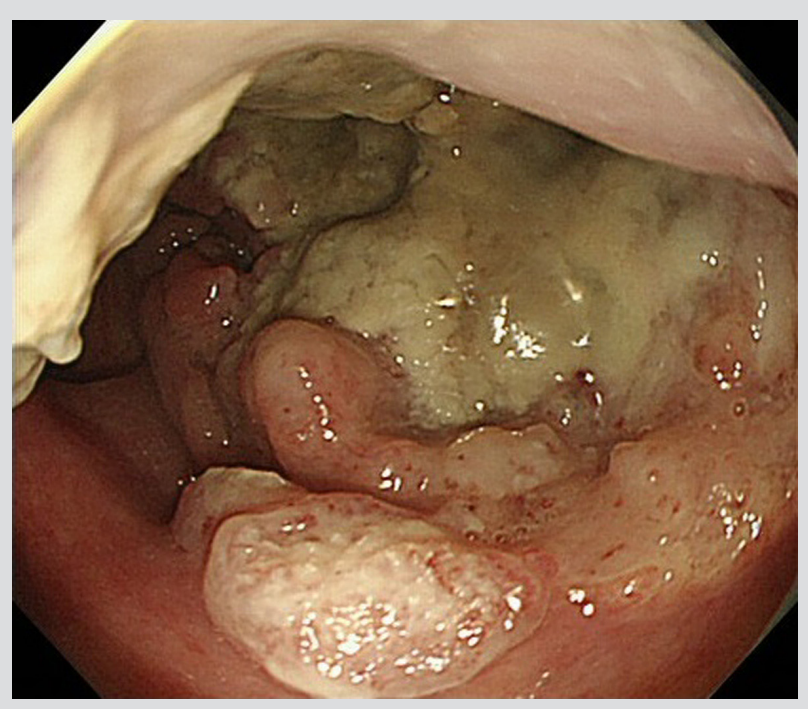

Figure 2. Esophagogastroduodenoscopy showing an advanced oropharyngeal cancer in the right glossotonsillar sulcus

\section{DISCUSSION}

Patients with esophageal squamous cell carcinoma are at high risk for second primary cancers. Head and neck cancer is one of the most common double cancers and develops in approximately $10 \%$ of patients with esophageal squamous cell carcinoma $a^{[1,2]}$.

The concept of field cancerization has been implicated in the pathogenesis of second primary head and neck cancer ${ }^{[3]}$. The pharynx is the most common site for cancer in the head and neck region, and pharyngeal cancer sometimes progresses to an advanced stage without symptoms. Therefore, the pharynx should be observed carefully when patients with esophageal squamous cell carcinoma undergo EGD.

Endoscopic screening method for the head and neck region has not been standardized including in Japan where endoscopists are more interested in the head and neck region than in most countries. Except for esophagus specialists, most endoscopists are still unfamiliar with monitoring the pharynx because they consider the pharynx to be the field of otorhinolaryngologists. Indeed, some endoscopists do not observe the pharynx at all. Therefore, even advanced oropharyngeal cancers such as the present case can be easily missed during EGD.

Patient vocalization during pharyngeal observation can facilitate observation of pharyngeal area whereas the gag reflex usually obscures an endoscopic view. To reduce the gag reflex, sedation with benzodiazepines or propofol is often performed during EGD. However, it usually prevents patients from vocalizing and obscures an endoscopic view of the pharynx, contrary to expectation.

Sedation with narcotic drugs can reduce the gag reflex but still allows patients to vocalize and offer adequate conditions for pharyngeal observation during $E G D^{[4]}$.

\section{REFERENCES}

1. Katada C, Muto M, Tanabe S, Higuchi K, Sasaki T, Azuma M et al. Surveillance after endoscopic mucosal resection or endoscopic submucosal dissection for esophageal squamous cell carcinoma. Dig Endosc 2013;25 Suppl 1:39-43.

2. Kato M, Ishihara R, Hamada K, Tonai Y, Yamasaki Y, Matsuura N et al. Endoscopic surveillance of head and neck cancer in patients with esophageal squamous cell carcinoma. Endosc Int Open 2016;4:E752-E755.

3. Slaughter DP, Southwick HW, Smejkal W. Field cancerization in oral stratified squamous epithelium; clinical implications of multicentric origin. Cancer 1953;6:963-968.

4. Yamasaki Y, Ishihara R, Hanaoka N, Matsuura N, Kanesaka T, Akasaka T et al. Pethidine hydrochloride is a better sedation method for pharyngeal observation by transoral endoscopy compared with no sedation and midazolam. Dig Endosc 2017;29:39-48. 